\title{
INTRODUCTION: REGIONAL STUDIES OF THE CARIBBEAN
}

\author{
William R. Latham III*
}

Despite its proximity to the U.S., relatively few regional scientists have more than a passing familiarity with the Caribbean. Yet it offers a unique collection of diverse characteristics for regional studies: political statuses ranging from colonies and possessions to independent nations; resource endowments from rich to nonexistent; levels of development representing all stages; and integration into larger regional systems from minimal to total. Here the possibility of achieving ceteris paribus conditions naturally rather than as a statistical artifact is real. Here regional development policies can be observed operating almost in isolation, free from the complexities of larger, more advanced economies. And here, too, are opportunities for regional scientists to contribute to improving the welfare of real individuals through the application of regional analysis.

I welcomed the opportunity to assemble a set of papers on regional studies of the Caribbean both as a means of directing the attention of more mainland U.S. regional scientists toward the area, and of illustrating the state of regional science in the area. The region can benefit from more analysis and we can benefit from studying it.

The first paper illustrates a universal problem of regional analysis, the availability of data, that is especially acute in the Caribbean. In many parts of the region, good data are very scarce. This is especially true in the Dominican Republic, as the paper by Mulkey and Espinal shows. Their paper is almost purely descriptive; yet theirs is an important contribution. It is impossible for regional development programs to reduce an abstract concept called poverty. Poverty lives and breathes only among the people who are not merely affected by it, but are the stuff of which it consists. True understanding of the dimensions of the problem confronted by regional development policies begins with an understanding of the characteristics of the people of the region. Mulkey and Espinal provide such an understanding in an area where data are scarce. In fact, their paper illustrates one answer to the data availability problem: collect your own.

Kempe Ronald Hope's paper is also largely descriptive; he makes good use of limited data to document his description of the problems of underdeveloped Caribbean regions with rapidly growing populations. Hope finds evidence to support a number of traditional development hypotheses about sector differentiation and urbanization in four different Caribbean countries. He is able to clearly establish the connections among labor force participation, unemployment, and urbanization in Barbados, Guyana, Jamaica, and Trinidad and Tobago.

At the opposite ends of both the data availability and stage of development spectra from these four countries and the Dominican Republic must lie the Commonwealth of Puerto Rico. Here there is a relative wealth of data, though never enough to satisfy a regional analyst, as Newton and Sepulveda note in their analysis of revenue collections in Puerto Rico. Their paper shows that sophisticated methods can contribute measurably to improved government analysis. Even in the Caribbean region the statistical problems of simultaneity, two-stage least squares, and autoregression are important issues. The paper by Hill and Udall illustrates the ultimate in the use of data available from comprehensive regional income and product accounts. Their multiple equation regional econometric model has a structure par-

\footnotetext{
*Associate Professor, Department of Economics, University of Delaware.
} 
alleling a U.S. macroeconomic model. It is precisely the ideal that Lawrence Klein prescribed for regional econometric models before mainland modelers asserted its unattainability because the data were not available here. Hill and Udall's application of the model to the measurement of the impact of changes in the U.S. food stamp program is a good example of regional impact analysis with such an econometric model. They also effectively raise the economic dependency issue of regional development.

The dependency issue is raised again in a related area, the U.S. Virgin Islands, by William Boyer in his paper. He provides a useful history of the dependency of these U.S. possessions and shows how political status determines economic relations. He extends the dependency discussion into the present political arena in exploring the possibility of other statuses with more or less dependency for this region. He notes that Puerto Rico and the Virgin Islands are different from the rest of the decolonizing Caribbean because, for them, self-determination is a myth rather than a reality.

The final paper also deals with the Virgin Islands and with myth and reality in perception. McElroy and Albuquerque explain the extent and consequences for Virgin Islands economic development of the mistaken impression by U.S. policymakers that the area has the potential for independence. They document that it operates more like a regional subsystem of the U.S. The individual islands are more concerned with the U.S. Congress than they are with each other. McElroy and Albuquerque also draw out some implications of the Virgin Islands experience for the rest of the Caribbean, particularly in light of the present Caribbean Basin Initiative of the U.S. government.

Taken together these papers offer a taste, one that hopefully whets some appetites, of what regional studies of the Caribbean can do. 